\title{
Qualitative survey-based evaluation of operability and convenience for the etanercept biosimilar YLB113 in a unique injection pen in patients with rheumatoid arthritis
}

\author{
Toshihiko Hibino', MD; Tomohiko Yoshida², MD, PhD; Akira Sagawa3 , MD, PhD; lkuko Masuda ${ }^{4}$, MD, PhD; Takaaki \\ Fukuda ${ }^{5}, M D$
}

\begin{abstract}
Introduction/Study objective: Needle fear is common among patients with rheumatoid arthritis (RA) who require subcutaneous (SC) injections. The convenience, usability and safety of the etanercept biosimilar YLB113 in an injection pen were evaluated among patients who switched from syringe injection.

Methods: Patients with RA who had completed the phase III clinical study of YLB113 in a pre-filled syringe (YLB113-002) were enrolled $(n=35)$ and received once-weekly SC injections with the injection pen (YLB113 50 mg) for 8 weeks. After 8 weeks, patients completed a qualitative survey evaluating the form and design of the pen, its operability, and patient preference for pen or syringe. Adverse events were evaluated throughout the study.

Results: Most patients reported the pen was 'very easy to grasp' or 'easy to grasp.' The pen was also reported to be easy to operate. The click signalling the start and end of the injection could be heard 'very well' or 'well'. Similarly, the injection solution check window could be seen by most patients. About three-quarters of respondents preferred the pen over a syringe. The pen was considered easier to use for the following reasons: the body is easy to grasp; the procedure is easy to understand; and the procedure can be performed without anxiety, fear, or tenseness.

Conclusion: The majority of these Japanese subjects with RA in the study judged the YLB113 50 mg delivered by injection pen to be easy to use, convenient and well tolerated.
\end{abstract}

Keywords: Etanercept, injection pen, needle fear, rheumatoid arthritis, usability, YLB113

\section{Introduction/Study objective}

Needle fear is common among people with chronic conditions who require injections, including patients with rheumatoid arthritis (RA) [1, 2]. Indeed, approximately one in five people has a fear of needles [3, 4]. Patients who are afraid of needles are significantly more likely to avoid medical treatment compared with those who are not afraid of needles [2, 4]. Moreover, many patients with RA are resistant to changing from oral medications, such as methotrexate, to biological disease-modifying antirheumatic drug (bDMARD) injectable medications, even if they have worsening symptoms [5]. Injection experience has been cited as a reason for discontinuation of bDMARDs by more than half of patients who stopped biological therapy [6]. Among patients with other diseases requiring long-term injections, e.g. diabetes, the need for injectable medication has also been associated with non-adherence to therapy [7]. Factors associated with fear of injection may be modifiable by self-injection with an injection pen. For example, young adults are significantly more likely to have a fear of injections if they hear a nurse talk about the injection, watch a nurse prepare the syringe, or watch other people receive injections in the clinic [3]. Furthermore, injection pens have been reported to be easier to use, less painful, and associated with better adherence than syringes [8-10]. Reducing patient anxiety and increasing patient confidence have been shown to improve satisfaction levels with self-injection, which may explain why patients with RA prefer subcutaneous (SC) self-injections over intramuscular injections or intravenous infusions administered in a clinic [11-13].

YLB113 is a biosimilar candidate of etanercept that has been evaluated in a phase III trial, which showed that YLB113 has similar efficacy and safety profiles to the originator product [14]. Etanercept is a biological drug that treats autoimmune diseases by inhibiting tumour necrosis factor. Etanercept is indicated for the treatment of RA, juvenile RA, psoriatic arthritis, plaque psoriasis, and ankylosing spondylitis [15]. To evaluate the convenience and patient preference for a pen formulation of YLB113, patients in a phase III trial of YLB113 who switched from a pre-filled syringe to an injection pen were surveyed with a questionnaire.

\section{Methods}

Study design

Patients with RA who completed the phase III clinical study of YLB113 (YL Biologics) in syringe formulation (YLB113-002) were enrolled in the present study. The YLB113-002 study has been described in detail elsewhere [14]. Briefly, 528 patients from Europe, Japan, or India with moderate-to-severe RA receiving concomitant methotrexate were randomly assigned to receive YLB113 $(n=266)$ or etanercept reference product (Enbrel; $\mathrm{n}=262$ ), both of which were administered by prefilled syringe. After 24 weeks of treatment, the ACR20 response 
rate (a composite measure defined as $\geq 20 \%$ improvement in tender and swollen joint counts and $\geq 20 \%$ improvement in three of the following five criteria: patient global assessment, physician global assessment, functional ability measure, visual analogue pain scale, and erythrocyte sedimentation rate or C-reactive protein) was similar between groups: $87.1 \%$ for the reference product and $81.3 \%$ for YLB113.

A total of 241 Japanese patients completed YLB113-002. Japanese participants were enrolled in the present study in the order of completion, i.e. the first 35 patients who completed and submitted informed consent were enrolled in the present study. Patients submitted written consent to switch from the pre-filled syringe used in YLB113-002 to an injection pen. Patients selfadministered once-weekly SC injections with the injection pen $(50 \mathrm{mg}$ ) for a total of 8 weeks. Figure 1 shows a study flow of the cohort.

Figure 1: Study flow of the cohort

\section{Consort Diagram}

Japanese RA patients involved in the YLB113-002 phase III study $(n=201)$

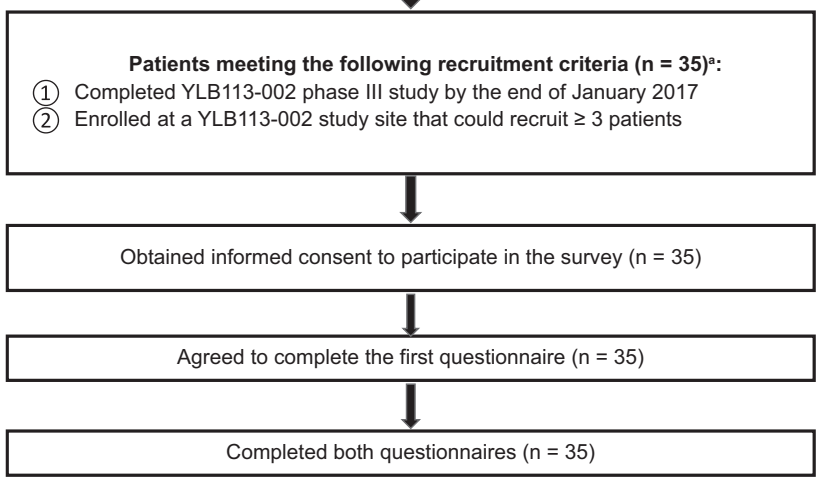

${ }^{a}$ The pen usability survey was administered in hospitals that could enroll $\geq 3$ patients in the survey study to ensure investigators were comfortable providing instructions to patients related to use of the injection pen. Recruitment was conducted in the order in which patients completed the phase III study.

At the start of the trial, patients were provided with YLB113 pen instructions for use and training regarding proper injection pen use. Participants were instructed to hold the injection pen in the vertical position and were informed about the possibility of insufficient injection. During training, patients simulated injection using an injection pen and a foam pad for practice. The first dose was then self-injected under the direction of a nurse or study collaborator.

Prior to enrolling in the 8-week survey study, participants responded to a survey that evaluated fear of injection, fear of self-injection, and injection pain using a syringe. At the end of the 8-week survey study, participants answered the same questions for the pen device. Patients also completed the selfinjection operability and convenience survey at the conclusion of the 8 weeks.

Adverse events were evaluated throughout the study.
This study protocol was reviewed and approved by the YL Biologics Ltd. Clinical Trial Review Committee registration and approval number: YLB-03-2016 (28 June 2016). The Pharmaceuticals and Medical Devices Agency accepted the study protocol on 8 July 2016 (Clinical Trial Number: 28-1652).

All procedures performed in studies involving human participants were in accordance with the ethical standards of the institutional and/or national research committee (YL Biologics Ltd. Clinical Trial Review Committee, registration number YLB-03-2016) and with the 1964 Declaration of Helsinki and its later amendments or comparable ethical standards. The ethics committee at each clinical site provided approval for study implementation.

This manuscript does not contain any studies with animals performed by any of the authors.

\section{YLB113 injection}

The unique YLB113 injection pen device is a pre-filled injection pen of etanercept. The injection pen is cylindrical, about $2 \mathrm{~cm}$ in diameter and $14 \mathrm{~cm}$ long, see Figure 2, with a 27 -gauge needle and 0.5 inches of exposed needle. Safety features include a green safety guard around the needle to prevent accidental needle sticks.

\section{Figure 2: YLB113 injection pen}

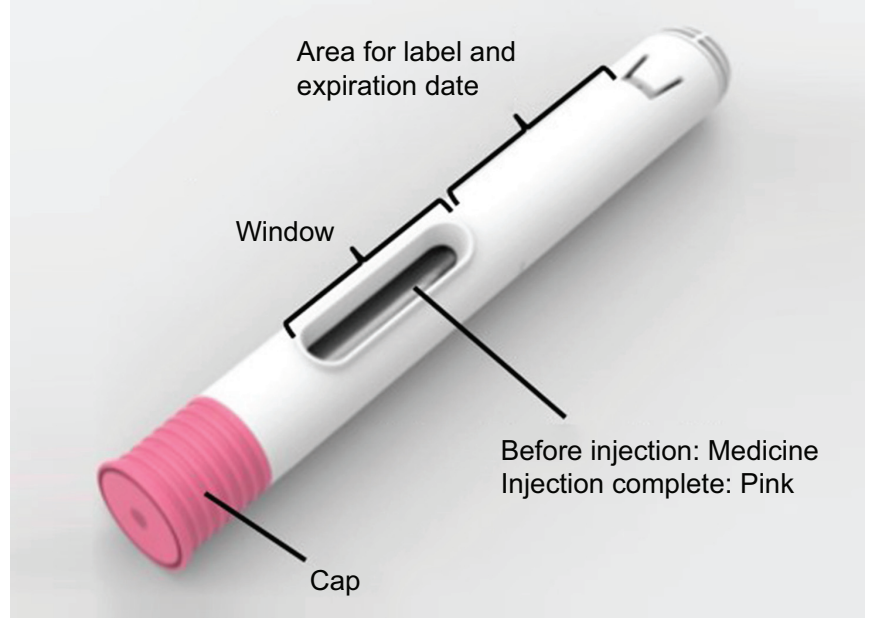

See the Appendix in the electronic supplementary materials for the full YLB113 instructions for use. Briefly, the pre-filled pen should be firmly pressed at a 90-degree angle into the skin to begin the injection. An audible click signals the beginning of the injection, and a second audible click signals the end of the injection. After the second click, users are instructed to count slowly to 15 to ensure the injection is complete before moving the pen.

\section{Qualitative operability and convenience survey}

Prior to the survey study, a formative human factors study of the YLB113 pen was conducted to identify human errors that may occur during self-injection of the device. Overall, the device was found to be easy to use, but many participants expressed 
concerns about self-injection due to fear of needles and injection pain. Based on the results of this human factors study, a survey was developed to qualitatively evaluate operability and convenience among patients who had previously used syringes to inject etanercept. Survey questions evaluated past self-injection experience, injection pen ease of use, injection pen operability, and preference for the injection pen or the pre-filled syringe. Patient opinions about the pen itself were also solicited in an open-answer format at the end of the survey. See the Appendix in the electronic supplementary materials for the full operability and convenience survey administered to patients.

\section{Results}

A total of 10 men and 25 women were enrolled in the study, see Table 1. No differences between men and women were reported for ACR (American College of Rheumatology) Global Functional Status or Disease Activity Score in 28 joints. The mean (standard deviation) age was 53.8 (11.2) years. The majority of patients (91.4\%) were experienced with self-injection with a pre-filled syringe prior to the start of the injection pen study. The remainder received their injections from a caregiver or healthcare provider throughout YLB113-002. Two patients performed self-injection for the first time during the injection pen study, and one patient elected to have a caregiver administer the injection throughout the study.

The form and design of the injection pen were evaluated in terms of appearance and ease of grip. Most patients reported finding the pen easy or very easy to grasp in terms of diameter, length, and overall body, see Table 2.

The operability of the injection pen was evaluated, see Table 3. In general, patients reported that the clicking feature that signals the start and end of the injection could be heard very well or well. Similarly, most patients reported that the injection solution check window could be seen well or could be seen. Opinions regarding the duration of injection were varied, with one-third of patients reporting the duration was 'just right', and others reporting it was long or short. A total of 5 (14.3\%) patients reported difficulty with pressing the tip of the injection pen vertically to the skin. Of these 5 patients, 4 reported that they had experienced injection spillage at least once. Spillage was defined as drug that was not injected into the patient and either pooled on the skin at or near the injection site or spilled from the needle as a result of incomplete injection.

\begin{tabular}{|c|c|c|c|}
\hline \multicolumn{4}{|c|}{$\begin{array}{l}\text { Table 1: Participant demographics at the start of the 8-week } \\
\text { operability and convenience study }\end{array}$} \\
\hline & $\begin{array}{c}\text { Men } \\
(n=10)\end{array}$ & $\begin{array}{l}\text { Women } \\
(n=25)\end{array}$ & $\begin{array}{l}\text { Overall } \\
(\mathrm{n}=35)\end{array}$ \\
\hline $\begin{array}{l}\text { Age, years; } \\
\text { mean (SD) }\end{array}$ & $53.4(9.1)$ & $54.0(12.1)$ & $53.8(11.2)$ \\
\hline $\begin{array}{l}\text { Height, cm; } \\
\text { mean }(\mathrm{SD})\end{array}$ & $171.6(5.8)$ & $156.4(6.8)$ & $160.7(9.5)$ \\
\hline $\begin{array}{l}\text { Body weight, } \\
\text { kg; mean (SD) }\end{array}$ & $70.1(10.4)$ & $56.3(15.8)$ & $60.2(15.7)$ \\
\hline $\begin{array}{l}\text { DAS28, } \\
\text { mean }(S D)\end{array}$ & $5.0(1.1)$ & $5.2(0.9)$ & $5.1(1.0)$ \\
\hline \multicolumn{4}{|c|}{ ACR Global Functional Status, n (\%) } \\
\hline Class 1 & $2(20)$ & $5(20)$ & $7(20)$ \\
\hline Class 2 & $8(80)$ & $18(72)$ & $26(74)$ \\
\hline Class 3 & 0 & $2(8)$ & $2(6)$ \\
\hline \multicolumn{4}{|c|}{ Experience with self-injection, $\mathrm{n}=35(\%)$} \\
\hline \multicolumn{3}{|c|}{ Have performed prior to study } & $32(91.4)$ \\
\hline \multicolumn{3}{|c|}{ Performed for first time during study } & $2(5.7)$ \\
\hline \multicolumn{3}{|c|}{$\begin{array}{l}\text { Have never performed (asked caregiver for } \\
\text { injection during study) }\end{array}$} & $1(2.9)$ \\
\hline
\end{tabular}

As seen in Figure 3, self-reported fear and pain decreased with use of the injection pen compared with use of the pre-filled syringe. At the start of the survey, 35 patients (100\%) reported they found injecting with a syringe either 'very scary' or 'a little scary'. At the end of the survey, 28 patients (80.0\%) reported they felt no fear using the injection pen, whereas five patients (4.7\%) found the injection pen 'a little scary'. Fear of selfinjection was also reduced, with 30 patients (85.6\%) reporting self-injection was 'very scary' or 'a little scary' with the syringe, which decreased to one patient (2.9\%) and five patients (14.3\%) reporting that the injection pen was 'very scary' or 'a little scary', respectively. Differences between syringe and pen injection were significantly different for all measurements, i.e. fear of needle for injection, fear of self-injection, and feeling of pain at injection; $\mathrm{p}<0.001$ Wilcoxon rank sum test.

Table 2: Form and design evaluation, surveyed at Week 8

\begin{tabular}{|l|c|c|c|c|c|}
\hline & \multicolumn{5}{|c|}{ Score, $\mathbf{n}(\%)$} \\
Appearance & $\begin{array}{c}\mathbf{5} \\
\text { Very good }\end{array}$ & $\mathbf{4}$ & $\begin{array}{c}\mathbf{3} \\
\text { Average }\end{array}$ & $\mathbf{2}$ & $\begin{array}{c}\mathbf{1} \\
\text { Very poor }\end{array}$ \\
\hline Appearance, including shape, size and colour & $8(22.9)$ & $9(25.7)$ & $17(48.6)$ & $1(2.9)$ & 0 \\
\hline Design & $\begin{array}{c}\mathbf{5} \\
\text { Very easy to grasp }\end{array}$ & $\mathbf{4}$ & $\begin{array}{c}\mathbf{3} \\
\text { Cannot say }\end{array}$ & $\mathbf{2}$ & $\begin{array}{c}\mathbf{1} \\
\text { Very difficult to grasp }\end{array}$ \\
\hline The diameter of the body & $6(17.4)$ & $22(62.9)$ & $5(14.3)$ & $2(5.7)$ & 0 \\
\hline The length of the body to grasp & $4(11.4)$ & $26(74.3)$ & $4(11.4)$ & $1(2.9)$ & 0 \\
\hline The body & $4(11.4)$ & $27(77.1)$ & $4(11.4)$ & 0 & 0 \\
\hline
\end{tabular}




\begin{tabular}{|c|c|c|c|c|c|c|}
\hline \multirow[b]{2}{*}{ Sound } & \multicolumn{6}{|c|}{ Score, n (\%) } \\
\hline & $\begin{array}{l}5 \\
\text { Could be heard } \\
\text { very well }\end{array}$ & 4 & \multicolumn{2}{|c|}{$\begin{array}{c}3 \\
\text { Sometimes could be } \\
\text { heard but other times } \\
\text { could not be heard }\end{array}$} & 2 & $\begin{array}{l}1 \\
\text { Could not hear } \\
\text { at all }\end{array}$ \\
\hline View & $\begin{array}{c}5 \\
\text { Could be seen well }\end{array}$ & 4 & \multicolumn{2}{|c|}{$\begin{array}{c}3 \\
\text { Cannot say }\end{array}$} & 2 & $\begin{array}{c}1 \\
\text { Could not see at all }\end{array}$ \\
\hline $\begin{array}{l}\text { The plunger (pink) in the injection solution } \\
\text { check window }\end{array}$ & 17 (48.6) & 17 (48.6) & \multicolumn{2}{|c|}{$1(2.9)$} & 0 & 0 \\
\hline Spillage from injection site & $\begin{array}{c}5 \\
\text { Never }\end{array}$ & 4 & \multicolumn{2}{|c|}{$\begin{array}{c}3 \\
\begin{array}{c}\text { Experienced a few } \\
\text { times }\end{array} \\
\end{array}$} & 2 & $\begin{array}{c}1 \\
\text { Experienced all the } \\
\text { time }\end{array}$ \\
\hline $\begin{array}{l}\text { Have you ever experienced the injection } \\
\text { solution spilling out from the injection site? }\end{array}$ & $19(54.3)$ & $11(31.4)$ & \multicolumn{2}{|c|}{$5(14.3)$} & 0 & 0 \\
\hline Pressing pen vertically & \multicolumn{3}{|c|}{$\stackrel{1}{1}$ Have experienced inability to press vertically } & \multicolumn{3}{|c|}{$\begin{array}{c}2 \\
\text { Have never experienced inability to } \\
\text { press vertically }\end{array}$} \\
\hline $\begin{array}{l}\text { When you press the tip of an injection pen } \\
\text { vertically on your skin, have you ever } \\
\text { experienced the inability to press it vertically? }\end{array}$ & \multicolumn{3}{|c|}{$5(14.3)$} & \multicolumn{3}{|c|}{$30(85.7)$} \\
\hline
\end{tabular}

When patients were asked to compare their experiences with the injection pen and syringe in the qualitative operability and convenience survey, most self-reported that their fear and anxiety 'decreased' or 'very much decreased' upon switching from syringe to injection pen, see Table 4. However, $42.9 \%$ of patients reported no change in a tense feeling related to selfinjection. About three-quarters of respondents preferred the injection pen to a syringe for ease of use. The reasons given for the ease of use of the injection pen included that the body was easy to grasp; the procedure was easy to understand; and the procedure was performed without anxiety, fear, or tenseness. Furthermore, most patients found the injection pen easier to use and planned to use the injection pen over the syringe.
Patients were asked for their opinions and requests for improvement for the injection pen. A total of five patients reported they would prefer reduced pain, and three reported a desire for a different infusion rate. Another common theme among patients was concern regarding the lack of control over injection duration and flow rate, which led to worry about the inability to stop the injection if they felt pain. Two women reported that they would like a smaller-sized injection pen.

No pen defects or treatment discontinuations occurred during the study. Among the 35 patients, 15 (42.9\%) reported adverse events associated with the use of YLB113. The most common adverse events were infections (17.1\%). Adverse events with a potential causal relationship to the study drug were reported in two patients: injection-site haemorrhage and hydronephrosis.

Table 4: Change in emotional state when transitioning from syringe to injection pen, surveyed at Week 8

\begin{tabular}{|c|c|c|c|c|c|}
\hline & \multicolumn{5}{|c|}{ Score, $\mathbf{n}(\%)$} \\
\hline Question & $\begin{array}{c}5 \\
\text { Very much } \\
\text { increased }\end{array}$ & 4 & $\begin{array}{c}3 \\
\text { No } \\
\text { change }\end{array}$ & 2 & $\begin{array}{c}1 \\
\text { Very much } \\
\text { decreased }\end{array}$ \\
\hline Fear of injection pen compared with that of pre-filled syringe & $3(8.6)$ & $3(8.6)$ & $9(25.7)$ & $12(37.1)$ & $7(20.0)$ \\
\hline Anxiety of injection pen compared with that of pre-filled syringe & $2(5.7)$ & $5(14.3)$ & $10(28.6)$ & $12(34.3)$ & $6(17.1)$ \\
\hline
\end{tabular}


Figure 3: Patient feelings about syringe injection

(a) Fear of needle for injection*

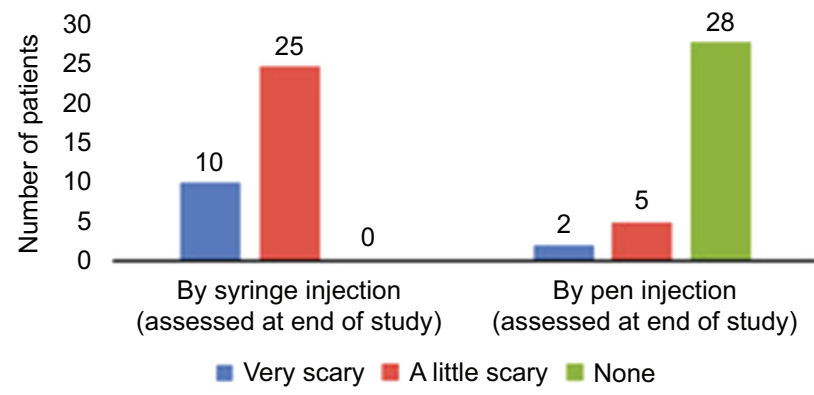

(b) Fear of self-injection*

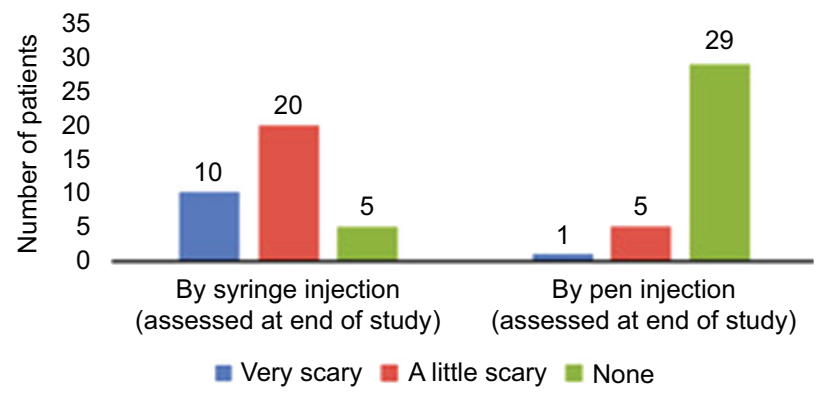

(c) Feeling of pain at injection*

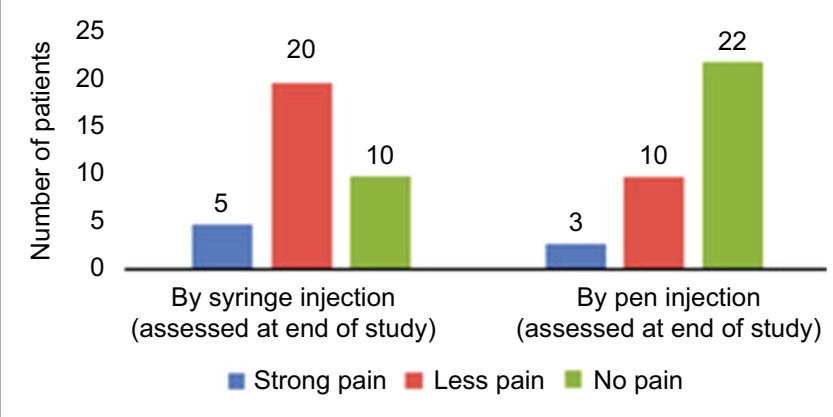

*Differences between syringe and pen injection were significantly different for all measurements ( $p<0.001$ by Wicoxon rank sum test).

One serious adverse event reported (otitis media) was deemed unrelated to the study drug.

\section{Discussion}

In this operability and convenience survey of patients with RA, 74\% of participants preferred self-injecting YLB113 with an injection pen over a pre-filled syringe. Participants reported that use of the injection pen was easier, more comfortable, and less fear-inducing than use of the syringe. A minority of patients (14\%), however, reported that the injection pen caused pain, and, because the injection pen procedure is not adjustable, they would prefer to use a syringe. Pain may be caused by a variety of factors, including the osmotic pressure of preparation, injection needle, device, infusion rate, and duration of injection.
In addition, patients reported that the injection pen was easy to grasp and easy to use. Although most patients could hear the first and second clicks, a small proportion (8.5\%) was unable to hear them, suggesting that users with hearing difficulty may be unable to hear the clicks. Redundant features, such as the pink colour in the viewfinder, are key to ensuring all patients can confirm complete injection. Except for one patient who 'could not say', all patients could see the pink plunger in the viewfinder window, indicating that even those patients with hearing difficulties can administer complete doses. This is important for the RA patient population, among whom hearing loss is common [16].

The benefits of an injection pen relative to a pre-filled syringe may be in part due to the ease of use of the device compared with a pre-filled syringe. Whereas administration of medication via a syringe requires the user to simultaneously press the device into the skin and depress a plunger, the YLB113 injection pen only requires the user to firmly press the cartridge to the injection site. This is relevant in patients with RA, among whom manual dexterity and grip strength may be impaired [17]. Furthermore, past studies have shown that patients with RA may prefer a button-free autoinjector, similar to the design of the YLB113 pen [18]. Other features that contribute to the ease of use of the YLB113 injection pen include the comfortable barrel size, the ridged cap for improved grasp, and the moderate level of force required to initiate injection. Finally, the cost of YLB113 is comparable to that of other etanercept formulations, and the cost of the injection pen is similar to that of a pre-filled syringe, further supporting use of the YLB113 pen.

The results of this study are in line with past prospective, controlled trials of the use of injection pens compared with the use of syringes. Patients with RA reported a preference for methotrexate delivered by an autoinjector instead of a pre-filled syringe regarding ease of use, acceptability and satisfaction [19]. These results have also translated to other chronic conditions that may require injections. For example, patients with ulcerative colitis found a golimumab autoinjector extremely easy or easy to use at a higher rate than golimumab injected via a pre-filled syringe (94.5\% vs 73.6\%) [20]. Furthermore, patients with ulcerative colitis reported moderate discomfort at a higher rate when using a pre-filled syringe (20.9\%) than when using an autoinjector (5.5\%) [20]. Similar results have been reported among patients with infertility and chronic kidney disease [21, 22].

Several limitations have been identified in this study. This is an observational study that did not have a control arm of patients receiving an injection via pre-filled syringe. However, all enrolled patients had previously received injection with a pre-filled syringe in a phase III trial, and therefore had experience with syringe injections of etanercept. Another limitation in this study is the self-reported nature of the results, which can introduce recall bias. Finally, a small number of patients were included in this study, and although several patients with severe disability were enrolled, the results may not be generalizable to the RA population as a whole. Additional studies in larger populations would be beneficial to better elucidate patient opinions of injection pen operability and convenience. Despite the limitations of the study, it is of note that the fear of injection decreased substantially among pen users who had 
previously used pre-filled syringes, suggesting that the YLB113 injection pen may be preferred among end users.

\section{Conclusion}

In conclusion, the results of a survey of 35 Japanese patients with RA suggest that the YLB113 injection pen was well tolerated and easy to use; and was preferred for etanercept injections.

\section{Clinical trials registration}

YL Biologics Ltd. Clinical Trial Review Committee registration and approval number: YLB-03-2016 (28 June 2016)

Pharmaceuticals and Medical Devices Agency Clinical Trial Number: 28-1652 (8 July 2016)

\section{Acknowledgements}

This study was conducted as a part of the phase III study conducted in Japan, which was controlled and funded by YL Biologics Ltd. TY, AS, IM, and TF are the clinical investigators who contributed to the clinical study in the hospitals. TH is responsible for the operation and is the main sponsor of the study, joined by the co-authors.

The authors would like to thank and acknowledge the following hospitals that participated in this study:

1. International Goodwill Hospital, Japan

2. Honjo Rheumatism Clinic, Japan

3. Suga Orthopedic Hospital, Japan

4. Kumamoto Shinto General Hospital, Japan

5. Fujimori Clinic, Japan

6. Rabbit Clinic, Japan

7. Chikamori Hospital, Japan

8. Kai Clinic, Japan

The authors would like to acknowledge YL Biologics Ltd for the clinical operations. YLB is the joint venture company between Yoshindo and Lupin, and Lupin contributed to its operation indirectly.

The YLB statistician team conducted the statistical analysis of the data and was supported by EPS.

The authors would like to thank the patients that participated in this study.

\section{Funding sources}

Funding for the phase III pen usability study, YLB113-003, was provided by YL Biologics Ltd. Editorial assistance was provided under the direction of the authors by The Lynx Group LLC. Funding support for editorial assistance was provided by YL Biologics Ltd.

\section{Authorship}

All named authors meet the International Committee of Medical Journal Editors (ICMJE) criteria for authorship for this manuscript, take responsibility for the integrity of the work as a whole, and have given their approval for this version to be published. Toshihiko Hibino, Tomohiko Yoshida, Akira Sagawa, Ikuko Masuda, and Takaaki Fukuda made substantial contributions to the conception or design of the manuscript, or the acquisition, analysis, or interpretation of data for the manuscript, and all authors were involved in drafting the manuscript or revising it critically for important intellectual content. The authors were fully responsible for all content and editorial decisions; and received no financial support or other form of compensation related to the development of this manuscript. All authors had final approval of the manuscript and are accountable for all aspects of the work in ensuring the accuracy and integrity of this manuscript.

\section{Compliance with ethics guidelines}

All procedures performed in studies involving human participants were in accordance with the ethical standards of the institutional and/or national research committee (YL Biologics Ltd. Clinical Trial Review Committee, registration number YLB-03-2016) and with the 1964 Declaration of Helsinki and its later amendments or comparable ethical standards. The ethics committee at each clinical site provided approval for study implementation.

This manuscript is based on previously conducted studies and does not contain any studies with human participants or animals performed by any of the authors.

\section{Data availability}

The datasets generated during and or analysed during the current study are available from the corresponding author at reasonable request.

Competing interests: Tomohiko Yoshida and Akira Sagawa declare no conflicts of interest. Ikuko Masuda has been a paid speaker for Teijin Pharma Ltd. Takaaki Fukuda has received consultant fees from YL Biologics Limited and has been a paid speaker for the following: Chugai Pharmaceutical, Takeda Pharmaceutical, Tanabe-Mitsubishi Pharmaceutical, Eisai Pharmaceutical, AbbVie Pharmaceutical, Astellas Pharmaceutical, AYUMI Pharmaceutical, Teijin Pharma Ltd., and Asahi Kasei Pharma. Toshihiko Hibino is an employee of YL Biologics Ltd and reports personal fees from YL Biologics Ltd during the conduct of this study.

Provenance and peer review: Not commissioned; externally peer reviewed.

\section{Authors}

Toshihiko Hibino ${ }^{1}$, MD

Tomohiko Yoshida ${ }^{2}$, MD

Akira Sagawa ${ }^{3}, \mathrm{MD}, \mathrm{PhD}$

Ikuko Masuda ${ }^{4}, \mathrm{MD}, \mathrm{PhD}$

Takaaki Fukuda 5 , MD

${ }^{1}$ YL Biologics Limited, Tokyo, Japan

${ }^{2}$ Setagaya Rheumatology Clinic, Tokyo, Japan

${ }^{3}$ Sagawa Akira Rheumatology Clinic, Sapporo, Japan

${ }^{4} J u j o$ Takeda Rehabilitation Hospital, Kyoto, Japan

${ }^{5}$ Koga Hospital 21, Kurume, Japan

\section{References}

1. Smolen JS, Aletaha D, McInnes IB. Rheumatoid arthritis. Lancet. 2016;388 (10055):2023-38. Erratum in Department of Error.

2. McLenon J, Rogers MAM. The fear of needles: a systematic review and metaanalysis. J Adv Nurs. 2019;75(1):30-42. 
3. Nir Y, Paz A, Sabo E, et al. Fear of injections in young adults: prevalence and associations. Am J Trop Med Hyg. 2003;68(3):341-4.

4. Wright S, Yelland M, Heathcote K, et al. Fear of needles-nature and prevalence in general practice. Aust Fam Physician. 2009;38(3):172-6.

5. Wolfe F, Michaud K. Resistance of rheumatoid arthritis patients to changing therapy: discordance between disease activity and patients' treatment choices. Arthritis Rheum. 2007;56(7):2135-42.

6. Bolge SC, Goren A, Tandon N. Reasons for discontinuation of subcutaneous biologic therapy in the treatment of rheumatoid arthritis: a patient perspective. Patient Prefer Adherence. 2015;9:121-31.

7. Davies MJ, Gagliardino JJ, Gray LJ, Khunti K, Mohan V, Hughes R. Real-world factors affecting adherence to insulin therapy in patients with Type 1 or Type 2 diabetes mellitus: a systematic review. Diabet Med. 2013;30(5):512-24.

8. Kivitz A, Cohen S, Dowd JE, Edwards W, Thakker S, Wellborne FR, et al. Clinical assessment of pain, tolerability, and preference of an autoinjection pen versus a prefilled syringe for patient self-administration of the fully human, monoclonal antibody adalimumab: the TOUCH trial. Clin Ther. 2006;28(10):1619-29

9. Slabaugh SL, Bouchard JR, Li Y, Baltz JC, Meah YA, Moretz DC. Characteristics relating to adherence and persistence to basal insulin regimens among elderly insulin-naïve patients with type 2 diabetes: pre-filled pens versus vials/syringes. Adv Ther. 2015;32(12):1206-21.

10. Miao R, Wei W, Lin J, Xie L, Baser O. Does device make any difference? A real-world retrospective study of insulin treatment among elderly patients with type 2 diabetes. J Diabetes Sci Technol. 2014;8(1):150-8.

11. Keininger D, Coteur G. Assessment of self-injection experience in patients with rheumatoid arthritis: psychometric validation of the Self-Injection Assessment Questionnaire (SIAQ). Health Qual Life Outcomes. 2011;9:2.

12. Fraenkel L, Bogardus S, Concato J, Felson DT, Wittink DR. Patient preferences for treatment of rheumatoid arthritis. Ann Rheum Dis. 2004;63(11):1372-8.

13. Louder AM, Singh A, Saverno K, Cappelleri JC, Aten AJ, Koenig AS, et al.
Patient preferences regarding rheumatoid arthritis therapies: a conjoint analysis. Am Health Drug Benefits. 2016;9(2):84-93

14. Yamanaka H, Kamatani N, Tanaka Y, Hibino T, Drescher E, Sánchez-Bursón $\mathrm{J}$, et al. A comparative study to assess the efficacy, safety, and immunogenicity of YLB113 and the etanercept reference product for the treatment of patients with rheumatoid arthritis. Rheumatol Ther. 2020;7(1):149-63.

15. Enbrel (etanercept) [package insert]. Thousand Oaks, CA: Amgen; 2017.

16. Murdin L, Patel S, Walmsley J, Yeoh LH. Hearing difficulties are common in patients with rheumatoid arthritis. Clin Rheumatol. 2008;27(5):637-40.

17. Palamar D, Er G, Terlemez R, Ustun I, Can G, Saridogan M. Disease activity, handgrip strengths, and hand dexterity in patients with rheumatoid arthritis. Clin Rheumatol. 2017;36(10):2201-08.

18. Thakur K, Biberger A, Handrich A, Rezk MF. Patient perceptions and preferences of two etanercept autoinjectors for rheumatoid arthritis: findings from a patient survey in Europe. Rheumatol Ther. 2016;3(2):245-56.

19. Demary W, Schwenke H, Rockwitz K, et al. Subcutaneously administered methotrexate for rheumatoid arthritis, by prefilled syringes versus prefilled pens: patient preference and comparison of the self-injection experience. Patient Prefer Adherence. 2014;8:1061-71.

20. Vermeire S, D'heygere F, Nakad A, Franchimont D, Fontaine F, Louis E, et al. Preference for a prefilled syringe or an auto-injection device for delivering golimumab in patients with moderate-to-severe ulcerative colitis: a randomized crossover study. Patient Prefer Adherence. 2018;12:1193-202.

21. Welcker JT, Nawroth F, Bilger W. Patient evaluation of the use of follitropin alfa in a prefilled ready-to-use injection pen in assisted reproductive technology: an observational study. Reprod Biol Endocrinol. 2010;8:111.

22. Lim WH, Chan D, Boudville N, Pellicano S, Herson H, Moody H, et al. Patients' perceptions of subcutaneous delivery of darbepoetin alfa by autoinjector prefilled pen versus prefilled syringe: a randomized, crossover study. Clin Ther. 2012;34(9):1948-53.

DOI: 10.5639/gabij.2020.0903.018

Copyright @ 2020 Pro Pharma Communications International

\begin{tabular}{|c|c|c|}
\hline 1 & Implementation status of self-injection & $\begin{array}{l}\text { 1. Have been performing self-injection of syringe-type preparation } \\
\text { 2. Experienced self-injection for the first time with this pen-type } \\
\text { preparation } \\
\text { 3. Have never experienced self-injection (have asked the caregiver } \\
\text { for injection) } \\
\text { 4. Others: }\end{array}$ \\
\hline 3 & $\begin{array}{l}\text { When you grasp the body of an injection pen, is the diameter right for } \\
\text { easy grasp? }\end{array}$ & $\begin{array}{l}\text { 1. Very easy to grasp } \\
\text { 2. Easy to grasp } \\
\text { 3. Cannot say } \\
\text { 4. Difficult to grasp } \\
\text { 5. } \\
\text { Very difficult to grasp }\end{array}$ \\
\hline
\end{tabular}




\section{Appendix: Compliance survey items (Continued)}

\begin{tabular}{|c|c|c|}
\hline Item \# & Question & Answer \\
\hline 5 & $\begin{array}{l}\text { How to hold the body of an injection pen is to grasp the body so that } \\
\text { you can see the injection solution check window, press the tip of the } \\
\text { pen vertically (at a 90-degree angle) at the injection site, and keep it } \\
\text { for } 15 \text { seconds. What do you think about ease of grasp of the body? }\end{array}$ & $\begin{array}{l}\text { 1. Very easy to grasp } \\
\text { 2. Easy to grasp } \\
\text { 3. Cannot say } \\
\text { 4. Difficult to grasp } \\
\text { 5. Very difficult to grasp }\end{array}$ \\
\hline 6 & $\begin{array}{l}\text { When you start injection, you will hear a clicking sound, and injection } \\
\text { will start. Did you hear the 'click'? }\end{array}$ & $\begin{array}{l}\text { 1. Could be heard very well } \\
\text { 2. Could be heard well } \\
\text { 3. Sometimes could be heard while other times could not be heard } \\
\text { 4. Difficult to hear } \\
\text { 5. Could not hear at all }\end{array}$ \\
\hline 7 & $\begin{array}{l}\text { When injection is started, the plunger (pink) of the check window starts } \\
\text { moving, and when a full amount of injection solution is injected, colour } \\
\text { of the entire window will change to pink. Could you see the end of } \\
\text { injection by the colour of the entire window changing to pink? }\end{array}$ & $\begin{array}{ll}\text { 1. } & \text { Could be seen well } \\
\text { 2. } & \text { Could be seen } \\
\text { 3. } & \text { Cannot say } \\
\text { 4. } & \text { Could not see } \\
\text { 5. } & \text { Could not see at all }\end{array}$ \\
\hline 9 & $\begin{array}{l}\text { To inject the injection solution completely, you need to keep pressing } \\
\text { the body of an injection pen at the injection site for } 15 \text { seconds. What } \\
\text { do you think about the duration of injection? }\end{array}$ & $\begin{array}{ll}\text { 1. } & \text { Very long } \\
\text { 2. } & \text { Long } \\
\text { 3. } & \text { Just right } \\
\text { 4. } & \text { Short } \\
\text { 5. } & \text { Very short }\end{array}$ \\
\hline 10 & $\begin{array}{l}\text { When you press the tip of an injection pen vertically on your skin, } \\
\text { have you ever experienced that you could not press it vertically (at a } \\
\text { 90-degree angle) but injected in that position? }\end{array}$ & 1. Have never experienced not being able to press vertically \\
\hline 11 & $\begin{array}{l}\text { Have you ever experienced the injection solution spilling out from the } \\
\text { injection site? }\end{array}$ & $\begin{array}{l}\text { 1. Never } \\
\text { 2. Experienced once } \\
\text { 3. Experienced a few times } \\
\text { 4. Experienced frequently } \\
\text { 5. Experienced all the time }\end{array}$ \\
\hline 13 & $\begin{array}{l}\text { In terms of the easy-to-hold, injection procedure, and easy-to-inject } \\
\text { nature of the body of devices, which one of syringe-type or pen-type } \\
\text { preparation is better? }\end{array}$ & $\begin{array}{l}\text { 1. Syringe-type is easier to use } \\
\text { 2. Pen-type is easier to use } \\
\text { 3. Ease of use is the same }\end{array}$ \\
\hline 14 & $\begin{array}{l}\text { Only persons who answered ' } 2 \text {. Pen type is easier to use' compared } \\
\text { with syringe-type to Question } 13 \text {, please answer this question. For the } \\
\text { reason for your answer ' } 2 \text {. Pen-type is easier to use,' please choose any } \\
\text { of the following as applicable. Persons who choose ' } 6 \text {. Others,' please } \\
\text { describe the other reason(s) in the parentheses (multiple answers are } \\
\text { acceptable). }\end{array}$ & $\begin{array}{l}\text { 1. The body is easy to grasp } \\
\text { 2. Self-injection procedure is easy to understand } \\
\text { 3. It is easy to understand from the start to the end of self-injection } \\
\text { 4. Self-injection turned out to be easier } \\
\text { 5. Because the needle is not visible, self-injection can be per- } \\
\text { formed without fear, anxiety, or a tense feeling } \\
\text { 6. Others } \\
\text { - Upon removal, injection pen causes less pain than needle } \\
\text { and syringe } \\
\text { The pen is safer because there is less chance of an accidental } \\
\text { needle stick prior to disposal }\end{array}$ \\
\hline \multirow[t]{2}{*}{15} & $\begin{array}{l}\text { In case of continued self-injection therapy after this questionnaire survey, } \\
\text { which preparation would you like to use? }\end{array}$ & $\begin{array}{l}\text { 1. Syringe-type preparation } \\
\text { 2. Pen-type preparation } \\
\text { 3. Either one is fine }\end{array}$ \\
\hline & $\begin{array}{l}\text { Please feel free to write your opinion/request for the pen-type } \\
\text { preparation }\end{array}$ & \\
\hline
\end{tabular}

